\title{
Isotopic and Chemical Characteristics of Lagoon Waters in Niigata Prefecture, Japan
}

\author{
Adilijiang Tiemuer ${ }^{1},{\text { Naoki } \mathrm{Kano}^{2}, \text { Hiroshi Imaizumi }^{2} \text { and Naoki Watanabe }}^{3}$ \\ 1. Graduation School of Science and Technology, Niigata University, Niigata 950-2181, Japan \\ 2. Department of Chemistry and Chemical Engineering, Faculty of Engineering, Niigata University, Niigata 950-2181, Japan \\ 3. Research Center for Natural Hazards and Disaster Recovery, Niigata University, Niigata 950-2181, Japan
}

\begin{abstract}
In order to investigate the isotopic and chemical characteristics of lagoon waters in Niigata Prefecture in recent years, oxygen and hydrogen stable isotope ratios (i.e., $\delta^{18} \mathrm{O}$ and $\delta \mathrm{D}$ ), the concentrations of DOC (dissolved organic carbon), DO (dissolved oxygen) and $\mathrm{pH}$, etc. in water samples of Sakata and Toyanogata were measured. Samples were generally taken monthly at the fixed sampling points from these lagoons. Consequently, the following matters have been mainly clarified: (1) $\delta \mathrm{D}$ value of water samples in Sakata was generally larger than that in Toyanogata similarly to the case of $\delta^{18} \mathrm{O}$, though remarkable large difference among samples was not found; (2) the $\mathrm{pH}$ value of lagoon water samples is almost 6.5-8.5 (which is generally larger than that of river water), and $\mathrm{pH}$ at the spot of S1 (downstream point of Lower Lagoon (Shitakata)) is remarkably high (9.0-9.5); (3) Lagoon water has the chemical characteristics contrasting to groundwater with a focus on river water from the viewpoint of $\mathrm{pH}$ (acidity or alkalinity) and DO. These matters can be closely related to the biological activity such as photosynthesis due to aquatic plant and phytoplankton and the activity of Crustacea plankton etc. in lagoon.
\end{abstract}

Key words: Lagoon water, oxygen and hydrogen stable isotopic ratio, DOC, DO, Niigata Prefecture.

\section{Introduction}

Oxygen and hydrogen stable isotopes (i.e., $\delta^{18} \mathrm{O}$, $\delta \mathrm{D})$ serve as useful tool for characterizing the origin of local waters and local hydrological cycle. These data supply some important hydrological information such as estimating the groundwater recharge, the movement of water in soils, the origin of the atmospheric vapor or the conditions of rain formation [1-3]. Hence, studies using stable isotopes are becoming an increasingly valuable component of research in environmental sciences and have been widely performed in the world [1-6].

Niigata Prefecture (Hokuriku District, Japan) is located in the geographic position where the monsoon comes from the Continent [7]. Moreover, a large amount of snow falls every year in winter season. Thus, isotopic and chemical investigation of the water

Corresponding author: Naoki Kano, associate professor, research field: environmental influence evaluation, technology and dynamic analysis. E-mail: kano@eng.niigata-u.ac.jp. samples in Niigata Prefecture is significant for the understanding of hydrologic environment in this area. However, hydrological and environmental investigations using oxygen and hydrogen isotopes (i.e., $\delta^{18} \mathrm{O}$ and $\delta \mathrm{D}$ ) as tracers have been little reported in Niigata Prefecture.

Then the characteristics of precipitation samples in Niigata Prefecture by using $\delta^{18} \mathrm{O}$ and other measuring items have been investigated in previous papers [8-10].

In this study, the main subject is focused on the environmental characteristics of lagoon waters in Niigata Prefecture. In case of lake or lagoon waters, water pollutions due to nutrients or organic materials have been observed in recent years [11, 12]. Therefore, regular monitoring and measurement of DOC (dissolved organic carbon) or DO (dissolved oxygen) in lagoon waters as simple index of the pollutants is also significant from the viewpoint of environmental protection. 
Considering the above-mentioned, in addition to the measurement of $\delta^{18} \mathrm{O}$ and $\delta \mathrm{D}$, the concentrations of DOC and DO in water samples of Sakata and Toyanogata were determined in the present work to investigate the environmental characteristics of lagoon waters in Niigata Prefecture in recent years.

\section{Materials and Methods}

\subsection{Samples}

Lagoon water samples were usually taken monthly from the fixed sampling points (five points) from two lagoons (Sakata and Toyanogata) in Niigata Prefecture, Japan. These five sampling points are shown in Fig. 1. The general features of these two lagoons are briefly as follows.

Sakata is famous for the wetland registered "Ramsar Covention", and has a water area of 43.6 ha. Sakata comprises a large ("Honkata" or "Shitakata") and a small ("Uwakata") freshwater lake with low bogs on the banks. This lake is situated near the major rice cropland in Japan, and was originally formed in an ancient hollow in the seaside dune. The lake has no inflow, and the water is supplied from groundwater of the dune. On the other hand, Toyanogata is the largest lake in Niigata Prefecture (lake area: 162 ha) and is located near the center of Niigata City. The lake is classified as "the first class river" (Water Systems of Shinano River), and flows into Kurinoki River.

\subsection{Analytical Method}

For the measurement of oxygen stable isotope ratios $\left(\delta^{18} \mathrm{O}\right), \mathrm{CO}_{2}-\mathrm{H}_{2} \mathrm{O}$ isotope equilibration method was performed [13]. The sample preparation procedure was the same as described in previous paper [8]. For the measurement of hydrogen stable isotope ratios $(\delta \mathrm{D}), \mathrm{H}_{2}-\mathrm{H}_{2} \mathrm{O}$ isotope equilibration method with Pt catalyst based on Coplen et al. [14] was used. Isotopic measurements were performed with a stable isotope ratio mass spectrometer (Micromass PRISM).

The concentrations of DOC, which is measured by converting all the organic material in sample waters to $\mathrm{CO}_{2}$ [15], was determined by a TOC (total organic carbon) Meter (SHIMADZU, 5050A). Basic physical parameters such as water temperature, $\mathrm{pH}, \mathrm{EC}$ (electric conductivity), ORP (oxidation-reduction potential) and DO in samples were measured at the sampling sites by a handy $\mathrm{pH} / \mathrm{COND}$ (conductivity) and $\mathrm{pH} / \mathrm{DO}$ Meter (HORIBA, D-24 and D-25).

\section{Results and Discussion}

3.1 Seasonal Behavior of $\delta^{18} O$ and $\delta D$ Values in Lagoon Waters in Niigata Prefecture

Seasonal behaviors of $\delta^{18} \mathrm{O}$ and $\delta \mathrm{D}$ of water samples
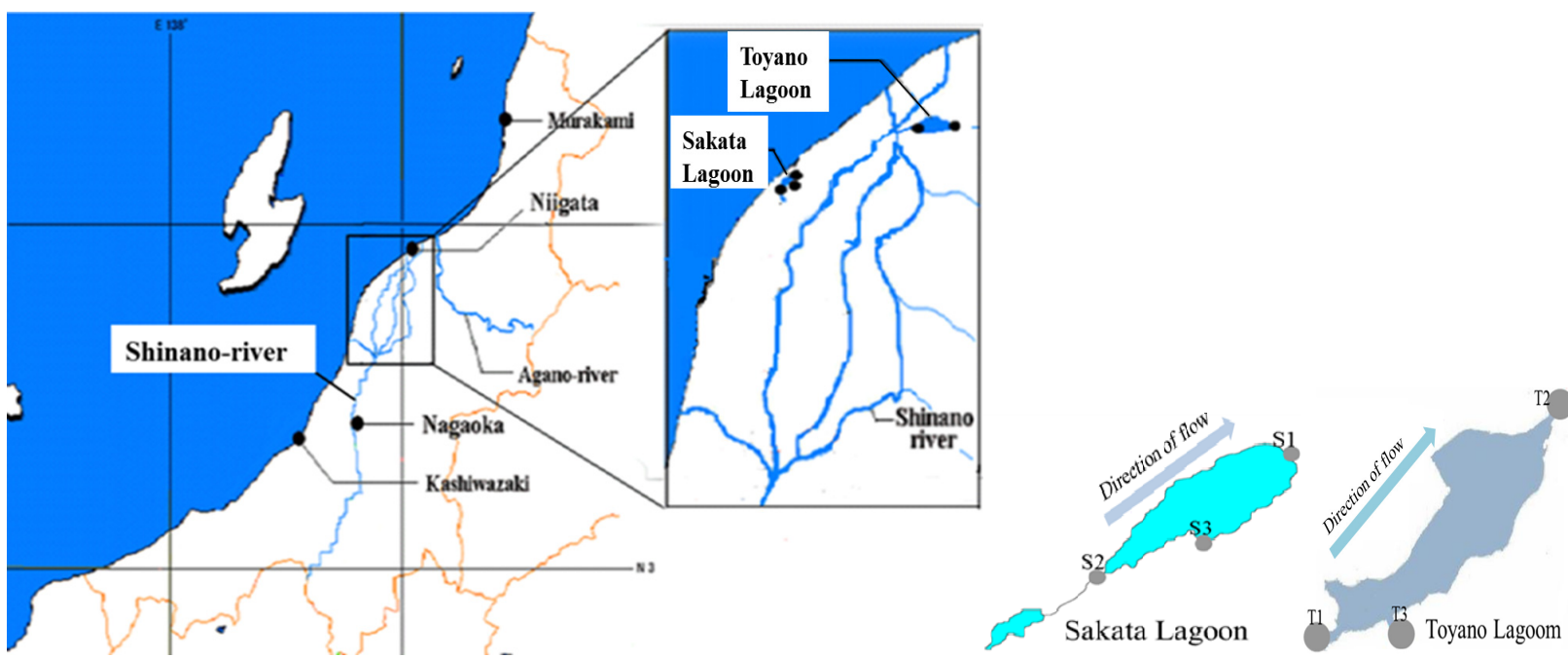

Fig. 1 Sampling points of Sakata and Toyanogata lagoon waters in Niigata Prefecture. 
at five points from two lagoons in Niigata Prefecture are shown in Fig. 2.

From Fig. 2, $\delta \mathrm{D}$ value of water samples in Sakata was generally larger than that in Toyanogata similarly to the case of $\delta^{18} \mathrm{O}$, though remarkable large difference among samples was not found.

In previous paper [16], $\delta^{18} \mathrm{O}$ of in these lagoon water (and river water) samples were measured. Consequently, it is found that the $\delta^{18} \mathrm{O}$ values of water samples in Sakata were larger than those in Toyanogata and in Shinano River as shown in Fig. 3, and that $\delta^{18} \mathrm{O}$ value in one of these samples (i.e. Sakata 1) is particularly large in summer.

The cause of large $\delta^{18} \mathrm{O}$ in Sakata has been estimated as the following possibility: (1) the effect of evaporation; (2) the activation of biological effect such as plankton; (3) the recharge from the

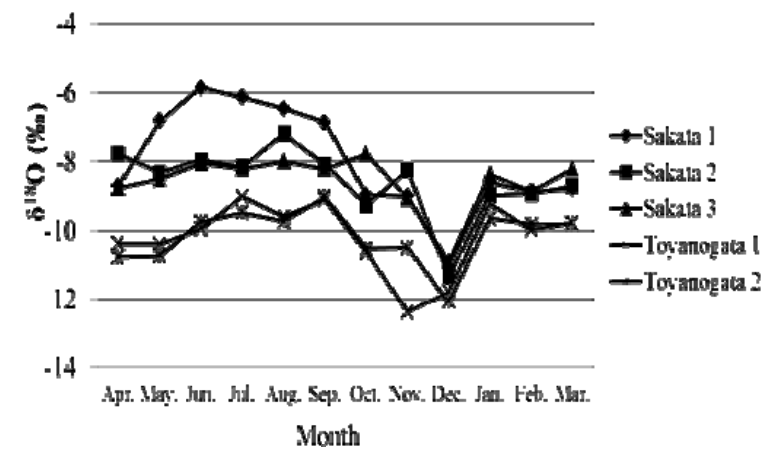

(a) surrounding groundwater.

It is known that zooplankton is found both in Sakata and in Toyanogata. However, Crustacea plankton (i.e., zooplankton having $\mathrm{CaCO}_{3}$ on shell) exists only in Sakata according to the statistical data from Environmental Management Division in Niigata City.

From the above-mentioned matter, it is suggested that larger $\delta^{18} \mathrm{O}$ found in water sample of Sakata particularly in summer is closely related to the activity of Crustacea plankton. That is to say, it is considered that the $\mathrm{O}$ (oxygen) of this sample is enriched in ${ }^{18} \mathrm{O}$ due to the following exchange reaction with the $\mathrm{O}$ of $\mathrm{CaCO}_{3}$ included in Crustacea plankton.

$$
3 \mathrm{H}_{2}{ }^{16} \mathrm{O}+\mathrm{CaC}^{18} \mathrm{O}_{3} \rightleftharpoons 3 \mathrm{H}_{2}{ }^{18} \mathrm{O}+\mathrm{CaC}^{16} \mathrm{O}_{3}
$$

Moreover, the effect of the recharge from the surrounding groundwater is also considered for explaining high $\delta^{18} \mathrm{O}$ values of waters in Sakata. As

0

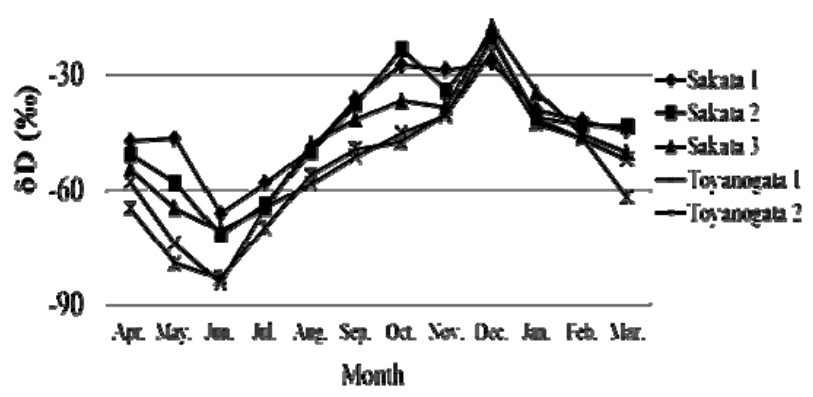

(b)

Fig. 2 Monthly variation of (a) $\delta^{18} \mathrm{O}$ and (b) $\delta \mathrm{D}$ in sample waters of Sakata and Toyanogata.

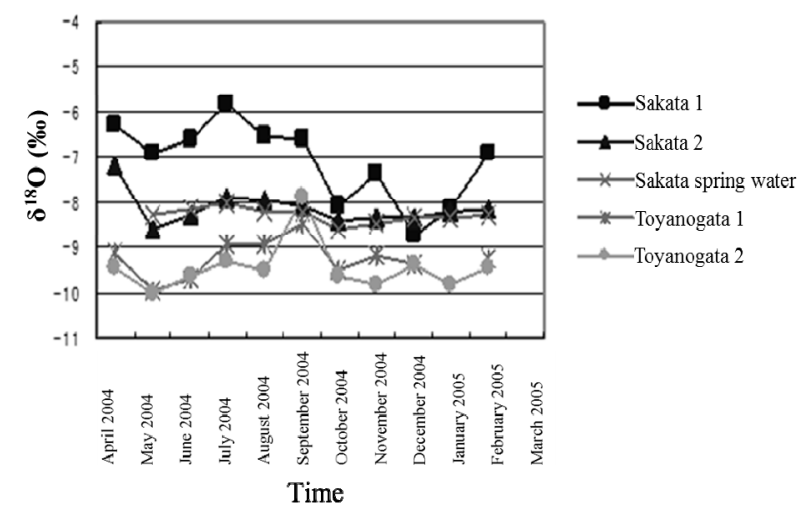

(a)

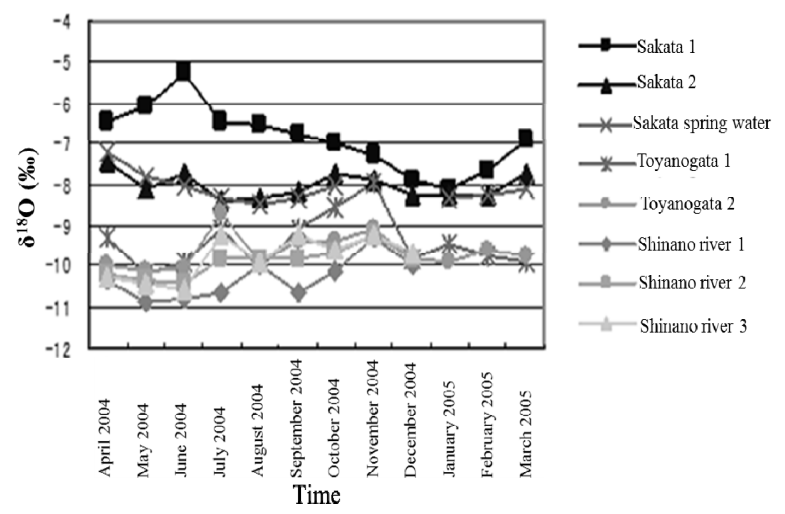

(b)

Fig. 3 Monthly variation of $\delta^{18} \mathrm{O}$ in Sakata and Toyanogata in (a) 2004 and (b) 2005 (for reference, $\delta^{18} \mathrm{O}$ of samples at three points in Shinano River in 2005 are also shown). 
mentioned in previous paper [16], $\delta^{18} \mathrm{O}$ values of five ambient well water samples around Sakata was $-8.53 \%$ to $-8.22 \%$, which was larger than those of representative river water or other groundwater samples in Niigata Prefecture. Then the sample water of Sakata may be strongly affected by the supply from groundwater.

From the results of isotopic analyses of $\delta \mathrm{D}$ (in addition to $\delta^{18} \mathrm{O}$ ) in this work, the biological effect based on Eq. (1) may be active in case of Sakata because $D$ value in summer was not larger than that in other season compered to $\delta^{18} \mathrm{O}$ values.

Then the sample water of Sakata is strongly affected by the supply from groundwater and/or the activity of crustacean plankton.

\subsection{Chemical Characteristics of Lagoon Waters in Niigata Prefecture}

Representative seasonal variations of $\mathrm{pH}$ of water samples at five points from Sakata and Toyanogata in Niigata Prefecture are shown in Fig. 4.

From Fig. 4, it is found that $\mathrm{pH}$ of lagoon water samples is 6.5-8.5 (which is generally larger than that of river water), and that $\mathrm{pH}$ at the spot of $\mathrm{S} 1$ (downstream point of Lower Lagoon (Shitakata)) is remarkably high (9.0-10.5). It might be attributable to photosynthesis due to aquatic plant and phytoplankton.

When these plants perform photosynthesis as following Eq. (2), $\mathrm{CO}_{2}$ are consumed in lagoon waters.

$$
6 \mathrm{CO}_{2}+6 \mathrm{H}_{2} \mathrm{O} \rightarrow \mathrm{C}_{6} \mathrm{H}_{12} \mathrm{O}_{6}+6 \mathrm{O}_{2}
$$

Furthermore, it is considered that consumed $\mathrm{CO}_{2}$ can be supplied from $\mathrm{HCO}_{3}{ }^{-}$(hydrogen carbonate ion), and $\mathrm{OH}^{-}$(hydroxide ion) are given off as following Eq. (3).

$$
\mathrm{HCO}_{3}^{-} \rightarrow \mathrm{CO}_{2}+\mathrm{OH}^{-}
$$

Then $\mathrm{pH}$ of the lagoon water shows basic by the release of $\mathrm{OH}^{-}$.

Seasonal variations of DO and DOC in the representative lagoon water samples from Sakata and Toyanogata in Niigata Prefecture are shown in Figs. 5 and 6, respectively. From Figs. 5 and 6, it is noted that the value of DO in Sakata is relatively large in summer (particularly in July) in spite of large value of DOC in summer. It suggested that the self-purification effect is existed in waters of Sakata because the dissolved oxygen is large in spite of large amount of organic materials. It may be related to photosynthesis of aquatic plants such as phytoplankton, considering it in conjunction with the results of above-mentioned $\mathrm{pH}$. On the other hand, remarkable seasonal behavior of DOC or DO is not found in water samples of Toyanogata.

Relationship between DO and water temperature in lagoon waters is shown in Fig. 7. For reference, the relationship in river waters and in groundwater in Niigata Prefecture is also shown. From Fig. 7, the data in river waters are mostly distributed around a certain curve (i.e., the solubility curve), which might be related to the fact that the solubility of gas is inversely proportional to water temperature.

In case of lagoon waters, the data are mostly distributed over the upper part of the curve, whereas

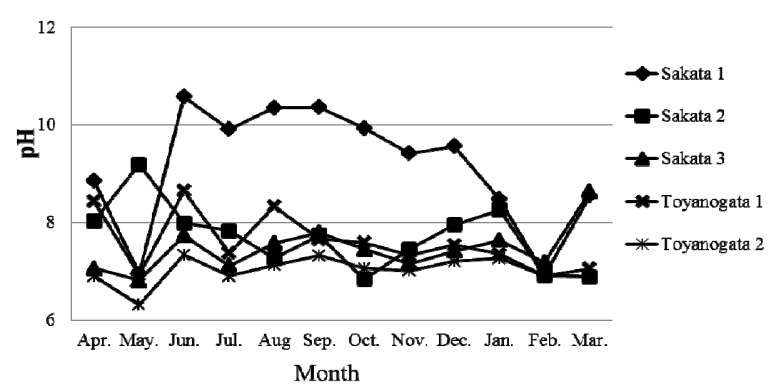

Fig. 4 Monthly variation of $\mathrm{pH}$ in Sakata and Toyanogata.

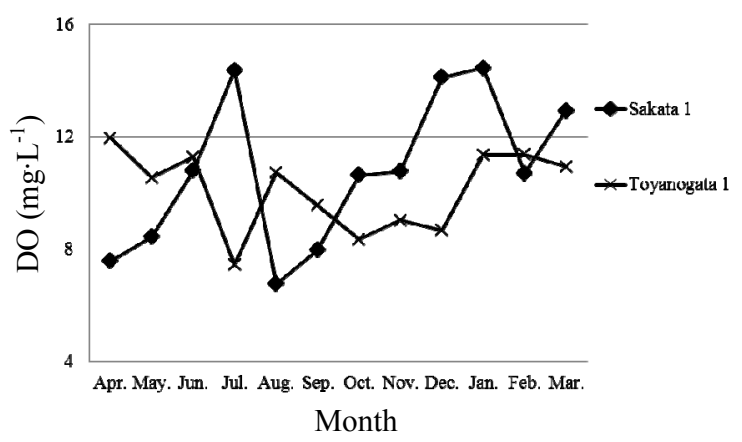

Fig. 5 Monthly variation of DO in Sakata and Toyanogata. 


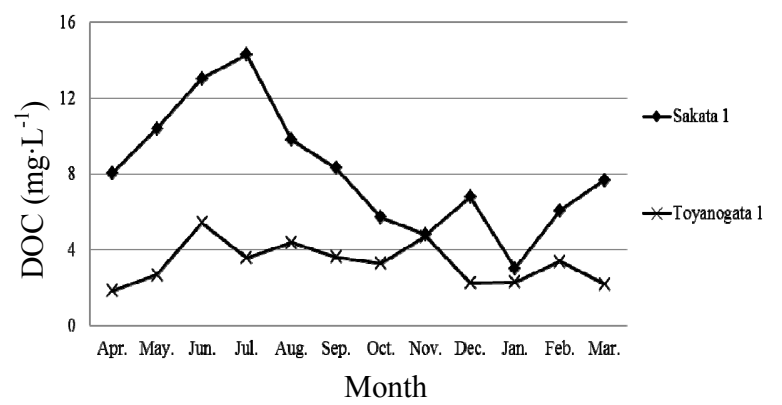

Fig. 6 Monthly variation of DOC in Sakata and Toyanogata.

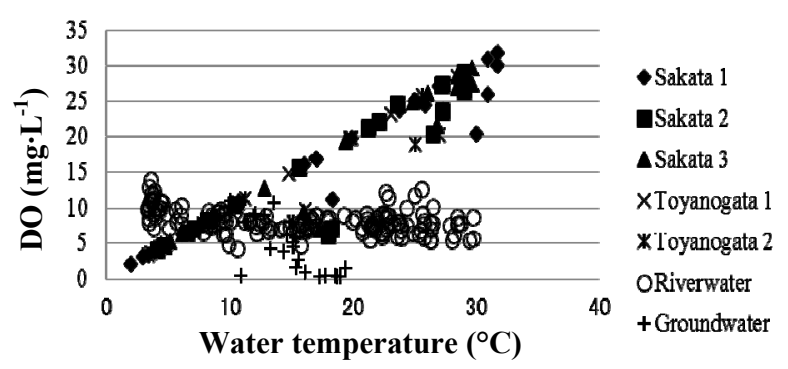

Fig. 7 Relationship between DO and water temperature in lagoon waters in Niigata Prefecture (For reference, the relationship in river waters and in groundwater is also shown).

the data in groundwater are mostly distributed over the bottom of the curve.

As mentioned above, in lagoon, the photosynthesis due to aquatic plant and phytoplankton may perform, which leads to the production of a large amount of oxygen, and generally attain to supersaturation state of oxygen. On the other hand, oxygen is considered to be consumed by the active activity of microbes in groundwater because it is generally in contact with soil or rock. Then oxygen is mainly in unsaturated state in groundwater, and $\mathrm{pH}$ of the water shows acidic by the release of $\mathrm{CO}_{2}$.

That is to say, it is suggested that lagoon water has the chemical characteristics contrasting to groundwater with a focus on river water from the viewpoint of $\mathrm{pH}$ (acidity or alkalinity) and DO.

\section{Conclusions}

For the investigation of the characteristics of lagoon waters in Niigata Prefecture, oxygen and stable isotopic ratios (i.e., $\delta^{18} \mathrm{O}$ ) as well as monthly variation of $\mathrm{pH}, \mathrm{DO}$ and $\mathrm{DOC}$ have been examined. It suggested that $\delta \mathrm{D}$ value of water samples in Sakata was generally larger than that in Toyanogata similarly to the case of $\delta^{18} \mathrm{O}$, though remarkable large difference among samples was not found. It can be closely related to the biological process such as the activity of Crustacea plankton and/or to the recharge from surrounding groundwater.

Moreover, it was found that $\mathrm{pH}$ value of lagoon water samples is 6.5-8.5 (which is generally larger than that of river water), and that $\mathrm{pH}$ at the spot of $\mathrm{S} 1$ (downstream point of Lower Lagoon (Shitakata)) is remarkably high (9.0-10.5). In addition, the value of DO in Sakata is relatively large in July in spite of large value of DOC in summer. These things might be attributable to photosynthesis due to aquatic plant and phytoplankton.

\section{Acknowledgments}

The present work was partially supported by a Grant-in-Aid for Scientific Research (Research Program (C), No. 25340083) of the Japan Society for the Promotion of Science. This research was also supported by a Fund for Promotion of Niigata University KAAB (Kariwa Village Advanced Agro-biotechnological Research Center) Projects from the Ministry of Education, Culture, Sports, Science and Technology, Japan.

\section{References}

[1] Abbott, M. D., Lini, A., and Bierman, P. R. 2000. " $\delta^{18} \mathrm{O}$, $\delta \mathrm{D}$ and $3 \mathrm{H}$ Measurements Constrain Groundwater Recharge Patterns in an Upland Fractured Bedrock Aquifer, Vermont, USA." Journal of Hydrology 228: 101-12.

[2] Kortelainen, M. N., and Karhu, A. J. 2004. "Regional and Seasonal Trends in the Oxygen and Hydrogen Isotope Ratios of Finnish Groundwaters: A Key for Mean Annual Precipitation." Journal of Hydrology 285: 143-57.

[3] Celle-Jeanton, H., Gonfiantini, R., Travi, Y., and Sol, B. 2004. "Oxygen-18 Variations of Rainwater during Precipitation: Application of a Rayleigh Model to Selected Rainfalls in Southern France." Journal of Hydrology 289: 165-77.

[4] Deshpande, R. D., Bhattacharya, S. K., Jani, R. A., and 
Gupta, S. K. 2003. "Distribution of Oxygen and Hydrogen Isotopes in Shallow Groundwaters from Southern India: Influence of a Dual Monsoon System." Journal of Hydrology 271: 226-39.

[5] Bauch, D., Erlenkeuser, H., and Andersen, N. 2005. "Water Mass Processes on Arctic Shelves as Revealed from $\Delta^{18} \mathrm{O}$ of $\mathrm{H}_{2} \mathrm{O}$." Global and Planetary Change 48: 165-74.

[6] Majumdar, N., Majumdar, R. K., Mukherjee, A. L., Bhattacharya, S. K., and Jani, R. A. 2005. "Seasonal Variations in the Isotopes of Oxygen and Hydrogen in Geothermal Waters from Bakreswar and Tantloi, Eastern India: Implications for Groundwater Characterization." Journal of Asian Earth Sciences 25 (2): 269-78.

[7] Kan, J., Cho, B. C., and Lee, C. B. 2010. "Atmospheric Transport of Water-Soluble Ions $\left(\mathrm{NO}_{3}^{-}, \mathrm{NH}_{4}{ }^{+}\right.$and Nss- $\mathrm{SO}_{4}{ }^{2-}$ ) to the Southern East Sea (Sea of Japan)." Science of Total Environment 408 (11): 2369-77.

[8] Kano, N., Kikuchi, T., Sakamoto, N., Imaizumi, H., Murayama, H., Yagoh, H., and Ohizumi, T. 2006. "Environmental Characteristics of Precipitations Based on Both Oxygen Stable Isotopic Ratio and Concentration of Rare Earth Elements (REEs), Thorium (Th), Uranium (U) in Niigata Prefecture." Radioisotopes 55: 307-17.

[9] Li, C., Kano, N., Ueno, Y., Hanabusa, M., Jiao, Y. R., Imaizumi, H., and Watanabe, N. 2010. "Characteristics of Oxygen Stable Isotopic Ratio in Precipitations in Niigata Prefecture, Japan.” Radioisotopes 59: 93-102.
[10] Tiemuer, A., Kano, N., Sasaki, M., Imaizumi, H., and Watanabe, N. 2014. "Oxygen Stable Isotopic Ratio in Precipitations in Niigata Prefecture, Japan." Journal of Environmental Science and Engineering 3: 229-39.

[11] Imai, A., Fukushima, T., Matsushige, K., and Kim, Y. H. 2001. "Fractionation and Characterization of Dissolved Organic Matter in a Shallow Eutrophic Lake, Its Inflowing Rivers, and Other Organic Matter Sources." Water Research 35: 4019- 28.

[12] Aoki, S., Fuse, Y., and Yamada, E. 2004. "Determinations of Humic Substances and Other Dissolved Organic Matter and Their Effects on the Increase Of COD in Lake Biwa." Anal. Sci. 20: 159-64.

[13] Epstein, S., and Mayeda, T. 1953. "Variation of ${ }^{18} \mathrm{O}$ Content of Water from Natural Sources." Geochim. et Cosmochim. Acta 4: 213-24.

[14] Coplen, T. B., Wildman, J. D., and Chen, J. 1991. "Improvements in the Gaseous Hydrogen-Water Equilibration Technique for Hydrogen Isotope-Ratio Analysis." Anal. Chem. 63: 910-2.

[15] Drever, J. I. 1997. The Geochemistry of Natural Waters: Surface and Groundwater Environments. 3rd ed.. Upper Saddle River, New Jersey: Prentice-Hall Inc..

[16] Lu, H., Kano, N., Yashima, Y., Amano, Y., Li, C., Imaizumi, H, Watanabe, N., and Zheng, Y. 2008. "Environmental Characteristics of Lagoon Waters in Niigata Prefecture Based on Oxygen Stable Isotopic Ratio and the Concentrations of Dissolved Materials." Radioisotopes 57: 405-18. 